\title{
Glucosamine, a naturally occurring amino monosaccharide modulates LL-37-induced endothelial cell activation
}

\author{
YINGHUA JU $^{1,4}$, JIAN HUA ${ }^{1}$, KOJI SAKAMOTO ${ }^{3}$, HIDEOKI OGAWA $^{2}$ and ISAO NAGAOKA ${ }^{1}$ \\ ${ }^{1}$ Department of Host Defense and Biochemical Research, ${ }^{2}$ Atopy (Allergy) Research Center, Juntendo University, \\ School of Medicine, Hongo, Bunkyo-ku, Tokyo 113-8421, ${ }^{3}$ Koyo Chemical Co., Ltd., Iidabashi, Chiyoda-ku, \\ Tokyo 102-0072, Japan; ${ }^{4}$ Department of Biochemistry and Molecular Biology, College of Basic \\ Medical Sciences, China Medical University, Shenyang 110001, P.R. China
}

Received June 12, 2008; Accepted August 1, 2008

DOI: 10.3892/ijmm_00000069

\begin{abstract}
Atheroscleros is now considered as a chronic inflammatory disease, and glucosamine has a potential to exhibit anti-inflammatory action. Thus, we investigated the effect of glucosamine on LL-37-induced endothelial cell activation. HUVEC (human umbilical vein endothelial cells) were stimulated by LL-37 in the presence or absence of glucosamine (0.01-1 mM) or its analogue, N-acetylglucosamine (0.1-1 mM). mRNA expression of MCP-1 (monocyte chemoattractant protein-1) and ICAM-1 (intercellular adhesion molecule-1) was evaluated by real-time RT-PCR, and their protein levels were analyzed by ELISA and Western blotting, respectively. Furthermore, the effect of glucosamine on $O$-N-acetylglucosamine $(O$-GlcNAc) modification was evaluated by Western blotting. Glucosamine but not $\mathrm{N}$-acetylglucosamine suppressed the LL-37-induced expression of MCP-1 and ICAM-1 at both mRNA ( $<<0.05$ at $0.1 \mathrm{mM})$ and protein levels $(\mathrm{p}<0.05$ at $1 \mathrm{mM})$. Of interest, $O$-GlcNAc modification was induced by incubating HUVEC with glucosamine ( $\mathrm{p}<0.05$ at $1 \mathrm{mM}$ ) but not $\mathrm{N}$-acetylglucosamine. Of note, alloxan, an $O$-N-acetylglucosamine transferase inhibitor, which prevented the glucosamine-induced $O$-GlcNAc modification, abrogated the suppressive effect of glucosamine on MCP-1 and ICAM-1 expression ( $\mathrm{p}<0.05$ at $0.5 \mathrm{mM}$ ). These observations suggest that glucosamine modulates endothelial cell activation possibly via $O$-GlcNAc modification, and may exhibit an anti-inflammatory action on atherosclerosis.
\end{abstract}

Correspondence to: Dr Isao Nagaoka, Department of Host Defense and Biochemical Research, Juntendo University, School of Medicine, 2-1-1 Hongo, Bunkyo-ku, Tokyo 113-8421, Japan

E-mail: nagaokai@juntendo.ac.jp

Key words: glucosamine, antimicrobial peptide, intercellular adhesion molecule-1, monocyte chemoattractant protein-1, endothelial cell

\section{Introduction}

In recent years many different clinical and pathological studies have altered the concept of pathogenesis of atherosclerosis. Although large lipid deposits can be seen in atheromatous lesions and the role of different lipoproteins are suggested in the pathogenesis of the disease, atherosclerosis is no longer considered to be a primary disorder of lipid accumulation (1). It is a state of disordered immunity in which there is dynamic interaction between endothelial dysfunction, inflammation and repeated cycles of 'wound healing response' (2). Expression of endothelial cell adhesion molecules such as intercellular adhesion molecule (ICAM-1), induces the binding of monocytes and $\mathrm{T}$ lymphocytes, thus initiating an inflammatory process that ultimately leads to the formation of atherosclerotic plaque (3). The migration of inflammatory cells into the subendothelial space is facilitated by chemoattractants such as monocyte chemoattractant protein-1 (MCP-1) (4) and oxidized low-density lipoprotein (5). Once migrated into the subendothelial space, monocytes mature into macrophages and express scavenger receptors to internalize modified lipoproteins, which gives rise to lipid-laden macrophages or foam cells (6).

In mammals at least two distinct families of antimicrobial peptides (AMPs) are identified. Defensins form a group with most representatives, and cathelicidin-derived antimicrobial peptides form a second group of AMPs. They are detected in blood, secretions, epithelial tissues and neutrophil granules, and exhibit potent antimicrobial activities against both Grampositive and -negative bacteria, fungi and certain viruses (7). Although many cathelicidin members have been isolated from mammals, only one cathelicidin has been identified in humans and named human cationic antibacterial protein of $18 \mathrm{kDa}$ (hCAP18) (8). The mature antibacterial peptide, LL-37 owes its name from its 37 -amino acid peptide with the two leading leucine residues. LL-37 was first detected in neutrophils, but later shown to be expressed in various epithelial cells, and specific lymphocyte and monocyte populations (9). LL-37 not only kill bacteria but also binds to LPS and blunt its biological activities (10). Furthermore, LL-37 possesses the ability to chemoattract immune and inflammatory cells, including neutrophils, monocytes and 
T lymphocytes via the action on a low affinity formylpeptide receptor-like 1 (FPRL1) (11). In addition, LL-37 suppresses neutrophil apoptosis via the activation of FPRL1 and $\mathrm{P} 2 \mathrm{X}_{7}$, a nucleotide receptor (12). Of importance, it has been recently revealed that LL-37 is expressed in the atherosclerotic plaques and involved in inflammatory responses in endothelial cells via the induction of ICAM-1 and MCP-1 expression, and vascular smooth muscle cell death $(13,14)$.

Glucosamine, a naturally occurring amino monosaccharide, is acting as a preferred substrate for biosynthesis of glycosaminoglycan, and is used for the treatment of osteoarthritis more than two decades in Europe (15). Several short- and long-term clinical trials in osteoarthritis have shown the significant symptom-modifying effect of glucosamine with no side effects (16). Furthermore, glucosamine is shown to inhibit the expression of inducible nitric oxide synthase in macrophages (17), and neutrophil functions such as superoxide generation, phagocytosis, granule enzyme release, chemotaxis and CD11b expression (18), thereby possibly exhibiting anti-inflammatory action. More recently, glucosamine has been revealed to inhibit ICAM-1 expression in human retinal pigment epithelial cells, which suggests the potential of glucosamine to attenuate inflammation in eyes (19). Based on these findings, we hypothesized that glucosamine may affect the endothelial cell activation. In this study, we investigated the effect of glucosamine on the activation of endothelial cells (expression of a monocyte chemoattractant factor MCP-1 and an adhesion molecule ICAM-1) induced by LL-37, an AMP expressed in the atherosclerotic lesions.

\section{Materials and methods}

Reagents. D-Glucosamine hydrochloride was supplied from Koyo Chemical Co. (Tokyo, Japan). N-Acetyl-D-glucosamine was purchased from Wako Pure Chemical Industries, Ltd. (Osaka, Japan). Alloxan monohydrate was purchased from Sigma Chemical Co. (St. Louis, MO). A 37-mer peptide of hCAP18 (LL-37; L1LGDFFRKSKEKIGKEFKRIVQRIKDF LRNLVPRTES ${ }^{37}$ ) was synthesized and purified, as previously described (10).

Endothelial cells. Human umbilical vein endothelial cells (HUVEC) and endothelial cell medium EGM-2 were purchased from Sanko Junyaku Co. (Tokyo, Japan). HUVECs were maintained in EGM-2 medium at $37^{\circ} \mathrm{C}$ in a $\mathrm{CO}_{2}$ incubator.

Analysis of MCP-1 and ICAM-1 mRNA expression by realtime $R T-P C R$. HUVEC were plated at $1.5 \times 10^{5} /$ well in 6 -well plates in EGM-2 medium for $24 \mathrm{~h}$ at $37^{\circ} \mathrm{C}$ (50-60\% confluent). The HUVEC were incubated in the presence or absence of 0.01-1 mM glucosamine or 0.1-1 mM N-acetylglucosamine for $2 \mathrm{~h}$, and then stimulated with $4 \mu \mathrm{M}$ LL-37 for $24 \mathrm{~h}$ at $37^{\circ} \mathrm{C}$. Thereafter, the total RNA was purified using an RNeasy Plus mini kit (Qiagen, Valencia, CA), and first-strand cDNA was synthesized with total RNA $(1 \mu \mathrm{g})$, a random primer and ReverTra Ace reverse transcriptase (Toyobo, Osaka, Japan) at $42^{\circ} \mathrm{C}$ for $20 \mathrm{~min}$, followed by termination at $99^{\circ} \mathrm{C}$ for $5 \mathrm{~min}$. Further, a quantitative real-time PCR was performed using
7500 Real-Time PCR system (Applied Biosystems, Warrington, UK). Reactions were carried out in a reaction mixture consisting of $25 \mu 1$ solution containing power SYBR Green PCR master mix (Applied Biosystems) and $200 \mathrm{nM}$ of each primer (ICAM-1, MCP-1 and GAPDH (glyceraldehyde 3-phosphate dehydrogenase) forward or reverse primer; Takara, Tokyo, Japan).

Analysis of MCP-1 protein expression by ELISA. HUVEC (50-60\% confluent in 24-well plates) were incubated in the presence or absence of 0.1-1 $\mathrm{mM}$ glucosamine or $0.1-1 \mathrm{mM}$ $\mathrm{N}$-acetylglucosamine for $2 \mathrm{~h}$, and then stimulated with $4 \mu \mathrm{M}$ $\mathrm{LL}-37$ for $24 \mathrm{~h}$ at $37^{\circ} \mathrm{C}$. The supernatants were removed and used for the quantification of MCP-1 protein using a Duoset MCP-1 ELISA development system (R\&D System, UK). In some experiments, HUVEC were preincubated with $0.5 \mathrm{mM}$ alloxan for $2 \mathrm{~h}$ and further incubated with $1 \mathrm{mM}$ glucosamine for $2 \mathrm{~h}$, before stimulation with $4 \mu \mathrm{M}$ LL-37.

Analysis of ICAM-1 protein expression by Western blotting. HUVEC (50-60\% confluent in 6-well plates) were incubated in the presence or absence of 0.1-1 $\mathrm{mM}$ glucosamine or 0.1-1 $\mathrm{mM}$ $\mathrm{N}$-acetylglucosamine for $2 \mathrm{~h}$, and then stimulated with $4 \mu \mathrm{M}$ LL-37 for $24 \mathrm{~h}$ at $37^{\circ} \mathrm{C}$. After washing with phosphate-buffered saline (PBS; $137 \mathrm{mM} \mathrm{NaCl}, 2.7 \mathrm{mM} \mathrm{KCl}, 8.1 \mathrm{mM} \mathrm{Na}_{2} \mathrm{HPO}_{4}$, $\left.1.5 \mathrm{mM} \mathrm{KH}_{2} \mathrm{PO}_{4}, \mathrm{pH} 7.4\right)$, the cells were recovered in $250 \mu \mathrm{l}$ of lysis buffer $(10 \mathrm{mM}$ Tris- $\mathrm{HCl}, \mathrm{pH} 7.4,1 \%$ Triton $\mathrm{X}-100$, $100 \mathrm{mM} \mathrm{NaCl}, 0.5 \%$ sodium deoxycholate, $1 \mathrm{mM}$ EDTA, $1 \mathrm{mM}$ EGTA and $1 \mathrm{mM}$ di-isopropyl fluorophosphate) containing 1/25 v/v Complete ${ }^{\mathrm{TM}}$ (Roche Diagnostics, Mannheim, Germany). Lysates were placed on ice for $30 \mathrm{~min}$, and centrifuged at $14,000 \mathrm{x} \mathrm{g}$ for $10 \mathrm{~min}$. The supernatants were recovered, and samples (10 $\mu \mathrm{g}$ protein/lane) were subjected to $10 \%$ sodium dodecyl sulfate (SDS)-polyacrylamide gel electrophoresis (PAGE). Separated proteins were transferred to polyvinylidene difluoride membrane (Millipore Corporation, Bedford, MA), and the membrane was blocked in 5\% skim milk and probed with rabbit anti-human ICAM-1 polyclonal antibody (H-108; Santa Cruz Biotechnology, Santa Cruz, CA). After washing with PBS-0.05\% Tween, the membrane was further probed with horseradish peroxidase (HRP)-conjugated goat anti-rabbit IgG (Chemicon International, Temecula, CA), and ICAM-1 was finally detected with a chemiluminescent substrate (Pierce, Rockford, IL). The detected bands were quantified using LAS-3000 image analyzer (Fujifilm Corporation, Tokyo, Japan).

Thereafter, the antibodies were stripped from the membrane using Restore Western stripping buffer (Pierce). GAPDH contained in each sample were detected with mouse antiGAPDH monoclonal antibody (MAB374, Chemicon International) and HRP-conjugated goat anti-mouse $\mathrm{IgG} / \mathrm{IgM}$ (Chemicon International). The protein contents were determined with a BCA protein assay kit (Pierce).

Detection of $\mathrm{O}-\mathrm{N}$-acetylglucosamine modification by Western blotting. HUVEC (50-60\% confluent in 6-well plates) were incubated in the presence or absence of $1 \mathrm{mM}$ glucosamine or $1 \mathrm{mM} \mathrm{N}$-acetylglucosamine for $2 \mathrm{~h}$, and then stimulated with $4 \mu \mathrm{M}$ LL-37 for $24 \mathrm{~h}$ at $37^{\circ} \mathrm{C}$. Alternatively, HUVEC were preincubated with $0.5 \mathrm{mM}$ alloxan for $2 \mathrm{~h}$ and further 
A
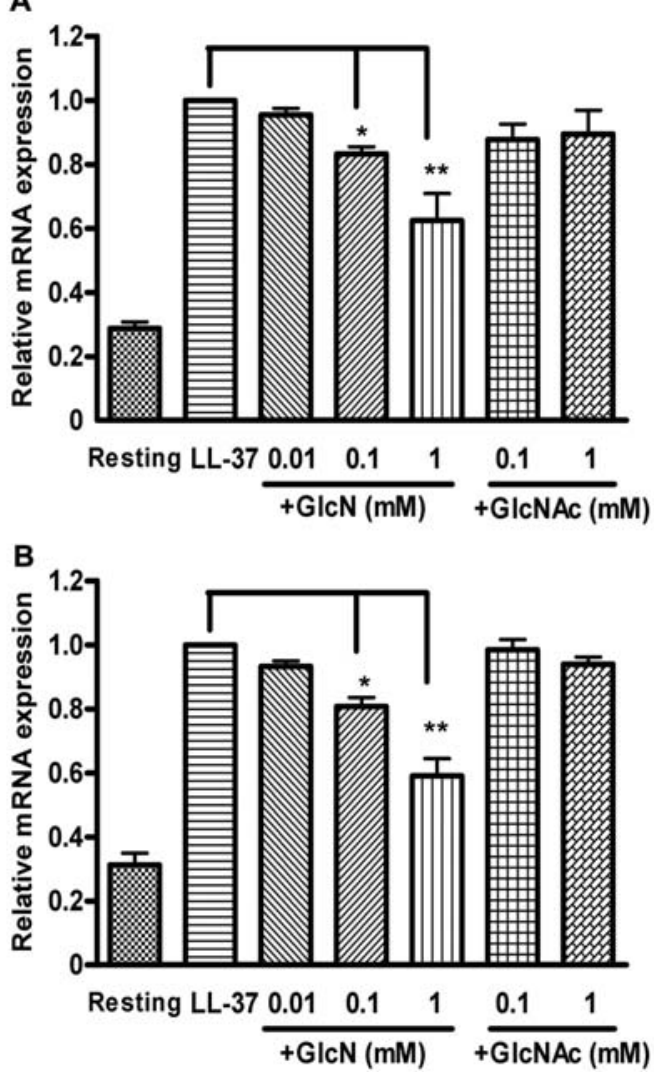

Figure 1. Effect of glucosamine on LL-37-induced MCP-1 and ICAM-1 mRNA expression in HUVEC. HUVEC were incubated without (Resting) or with $4 \mu \mathrm{M} \mathrm{LL}-37$ (LL-37) in the absence or presence of 0.01-1 mM glucosamine $(\mathrm{GlcN})$ or $\mathrm{N}$-acetylglucosamine (GlcNAc). MCP-1, ICAM-1 and GAPDH (a loading control) mRNA was detected by quantitative real-time RT-PCR. MCP-1 (A) and ICAM-1 (B) mRNA expression was expressed as a ratio relative to LL-37-stimulation alone. Data are mean \pm SEM from 4 independent experiments; ${ }^{*} \mathrm{p}<0.05,{ }^{* *} \mathrm{p}<0.01$.

incubated with $1 \mathrm{mM}$ glucosamine for $2 \mathrm{~h}$ before $4 \mu \mathrm{M}$ LL-37-stimulation. Samples (15 $\mu \mathrm{g}$ protein/lane) were applied to $7.5 \%$ SDS-PAGE, and the blotted membrane was immersed in $100 \%$ methanol and dried at room temperature. Then, the membrane was probed with mouse anti- $O$-GlcNAc ( $(-O$-linked $\mathrm{N}$-acetylglucosamine) monoclonal antibody (CTD110.6; Covance, Berkeley, CA) in $1 \%$ casein/PBS, and further probed with HRP-conjugated goat anti-mouse $\operatorname{IgG} / \operatorname{IgM}$ (Chemicon International) in $1 \%$ casein/PBS. The $O$-N-acetylglucosaminemodified proteins were detected, and analyzed, as described above.

Statistical analysis. Data are expressed as mean \pm SEM, and analyzed for significant difference by a one-way analysis of variance (ANOVA) with multiple comparison test or Student's t-test (Prism 4, GraphPad Software, San Diego, CA). Differences were considered statistically significant at $\mathrm{p}<0.05$.

\section{Results}

Effect of glucosamine on LL-37-induced expression of MCP-1 and ICAM-1 mRNA. To evaluate the effect of glucosamine on
A

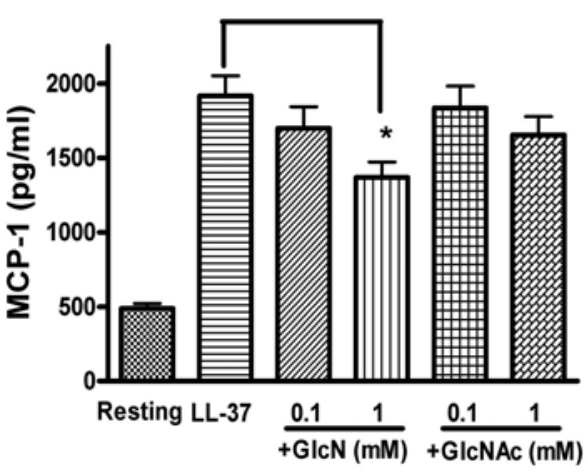

B
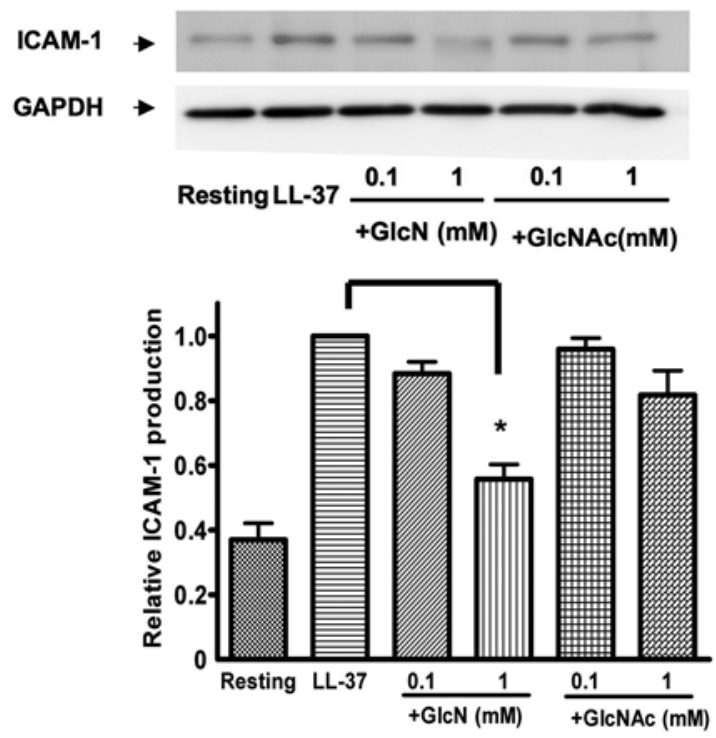

Figure 2. Effect of glucosamine on MCP-1 and ICAM-1 expression in HUVEC. HUVEC were incubated without (Resting) or with $4 \mu \mathrm{M}$ LL-37 (LL-37) in the absence or presence of 0.1-1 mM glucosamine (GlcN) or $\mathrm{N}$-acetylglucosamine (GlcNAc). The supernatants and cell lysates were recovered, and MCP-1 (A) and ICAM-1 (B) were quantitated by ELISA and Western blotting, respectively. ICAM-1 level was expressed as a ratio of LL-37-stimulation. Data are mean \pm SEM from 6 independent experiments for both MCP-1 and ICAM- $1 ;{ }^{*} \mathrm{p}<0.05$.

the MCP-1 and ICAM-1 mRNA expression, we stimulated HUVEC with LL-37, an AMP expressed in the atherosclerotic plaques, in the absence or the presence of glucosamine or $\mathrm{N}$-acetylglucosamine. As shown in Fig. 1, glucosamine dose-dependently inhibited the LL-37-induced expression of MCP-1 and ICAM-1 mRNA detected by real-time RTPCR ( $<<0.05$ at 0.1 and $1 \mathrm{mM}$ glucosamine). In contrast, $\mathrm{N}$-acetylglucosamine, an analogue of glucosamine, did not significantly affect the mRNA expression.

Effect of glucosamine on LL-37-induced expression of MCP-1 and ICAM-1 proteins. Since glucosamine inhibited the MCP-1 and ICAM-1 mRNA expression (Fig. 1), we next examined the effect of glucosamine on the LL-37-induced expression of MCP-1 and ICAM-1 proteins. Consistent with its suppressive effect on the mRNA expression, glucosamine inhibited the protein expression of MCP and ICAM-1 in a dose-dependent manner ( $\mathrm{p}<0.05$ at $1 \mathrm{mM}$ glucosamine) (Fig. 2). As expected, $\mathrm{N}$-acetylglucosamine gave no substantial effect on the protein expression. 
A

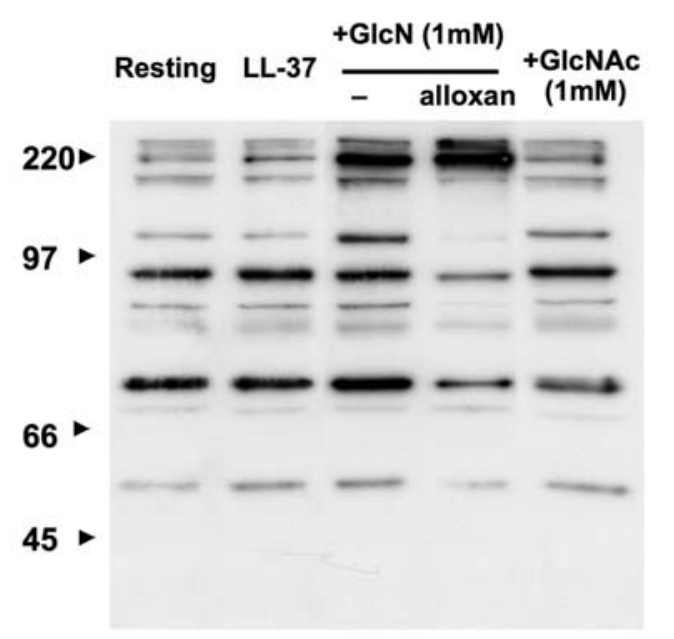

B

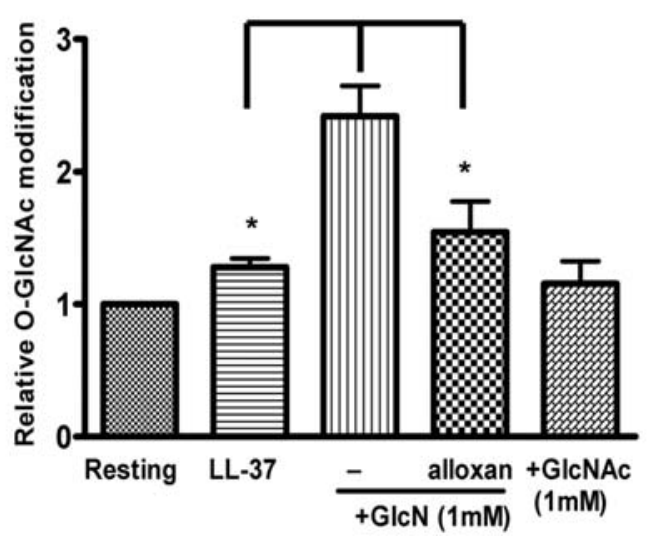

Figure 3. Glucosamine-induced O-GlcNAc modification in HUVEC. HUVEC were incubated without (Resting) or with $4 \mu \mathrm{M}$ LL-37 (LL-37) in the absence or presence of $1 \mathrm{mM}$ glucosamine $(\mathrm{GlcN})$ or $\mathrm{N}$-acetylglucosamine (GlcNAc). Alternatively, HUVEC were stimulated with $4 \mu \mathrm{M}$ LL-37 in the presence of glucosamine and alloxan $(0.5 \mathrm{mM})$. O-GlcNAc-modified proteins were evaluated by Western blotting (A). All the detected bands were quantified and summed up. O-GlcNAc modification levels were expressed as a ratio relative to Resting cells (B). Data are mean \pm SEM from 3 independent experiments; ${ }^{*} \mathrm{p}<0.05$.

Effect of glucosamine on O-GlcNAc modification. Modification of cellular proteins with $O$-linked-N-acetylglucosamine is involved in the modulation of cell functions, such as transcription and translation (20). Thus, we asked whether glucosamine induces $O$-GlcNAc modification, which accounts for the suppressive effect of glucosamine on endothelial cell activation. Preliminarily, we confirmed that glucosamine but not $\mathrm{N}$-acetylglucosamine dose-dependently induced the protein $O$-GlcNAc modification detected by Western blotting $(0.1,1$ and $10 \mathrm{mM})$ (data not shown). When the cells were stimulated with LL-37 in the presence of $1 \mathrm{mM}$ glucosamine, $O$-GlcNAc modification was observed $(\mathrm{p}<0.05)$, although LL-37 alone did not induce $O$-GlcNAc modification (Fig. 3). Of interest, alloxan, an inhibitor of $O$-GlcNAc modification, effectively prevented the glucosamine-induced $O$-GlcNAc modification $(\mathrm{p}<0.05)$ (Fig. 3). As expected, $\mathrm{N}$-acetylglucosamine did not essentially induce $O$-GlcNAc modification.

Effect of alloxan on the glucosamine-induced suppression of $M C P-1$ and ICAM-1 protein expression. Glucosamine inhibited MCP-1 and ICAM-1 expression but $\mathrm{N}$-acetylglucosamine did not. Similarly, glucosamine but not N-actylglucosamine
A

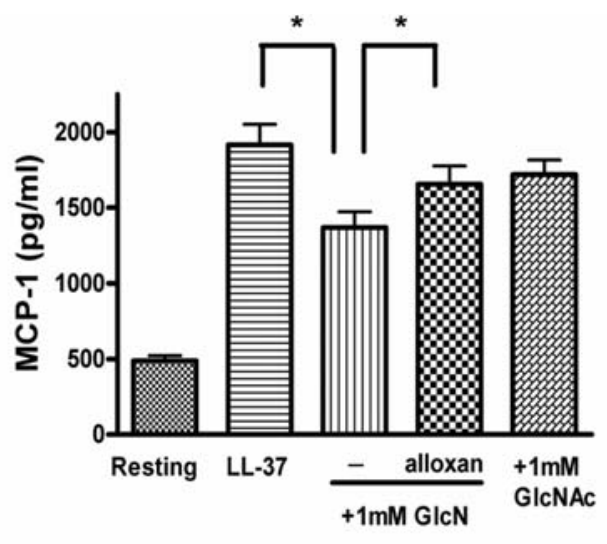

B

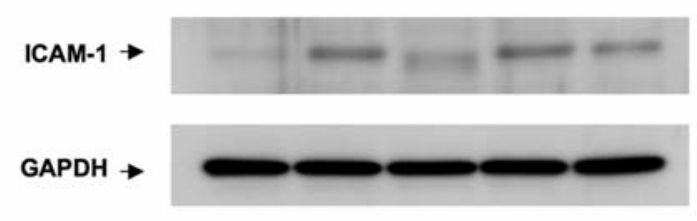

Resting LL-37 - alloxan +GIcNAc $\overline{+\mathrm{GlcN}(1 \mathrm{mM})}$ $(1 \mathrm{mM})$

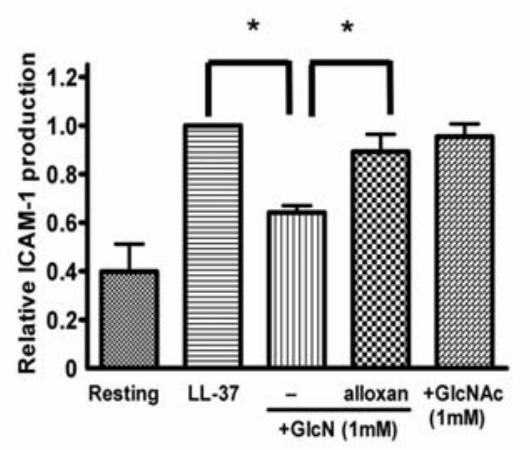

Figure 4. Effect of alloxan on the glucosamine-induced suppression of MCP-1 and ICAM-1 expression. HUVEC were incubated without (Resting) or with $4 \mu \mathrm{M}$ LL-37 (LL-37) in the absence or presence of $1 \mathrm{mM}$ glucosamine $(\mathrm{GlcN})$ or N-acetylglucosamine (GlcNAc). Alternatively, HUVEC were stimulated with $4 \mu \mathrm{M}$ LL-37 in the presence of glucosamine and alloxan $(0.5 \mathrm{mM})$. The supernatants were recovered, and MCP-1 was quantitated by ELISA (A). Cell lystaes were recovered, and ICAM-1 levels were evaluated by Western blotting (B). ICAM-1 expression was expressed as a ratio relative to LL-37-stimulation alone. Data are mean \pm SEM from 6 independent experiments for both MCP-1 and ICAM-1; ${ }^{*} \mathrm{p}<0.05$.

induced $O$-GlcNAc modification. Thus, we investigated the relationship between the glucosamine-induced $O$-GlcNAc modification and suppression of MCP-1 and ICAM-1 expression by using alloxan. Of importance, alloxan abrogated the glucosamine-induced suppression of MCP-1 and ICAM-1 expression $(\mathrm{p}<0.05)$ (Fig. 4) as well as glucosamine-induced O-GlcNAc modification (Fig. 3). These findings suggest the possible involvement of glucosamine-induced $O$-GlcNAc modification in the suppression of MCP-1 and ICAM-1 expression.

\section{Discussion}

LL-37 is the only cathelicidin member in humans, and exhibits antimicrobial activities against a broad spectrum of microbes in innate host defense system (7). Furthermore, LL-37 possesses the ability to chemoattract neutrophils, 
monocytes and T lymphocytes (11). LL-37 is expressed in not only neutrophils and epithelial tissues but also infiltrating macrophages and endothelial cells in atherosclerotic lesions, suggesting that LL-37 plays a role in the inflammatory process of atherosclerosis $(13,14)$. Edfeldt et al determined the effect of LL-37 on the atherosclerosis-related genes in HUVEC, and revealed that LL-37 can activate human endothelial cells and induce ICAM-1 and MCP-1 (13). As an adhesion molecule and a chemoattractant protein, they play important roles in the process of atherosclerotic plaque formation. Upon inflammatory activation, endothelial cells upregulate adhesion molecules (such as ICAM-1), and monocytes can bind to the endothelium through the adhesion molecules. Then, monocytes migrate into the arterial intima, and this process requires a chemoattractant (such as MCP-1) gradient. Once monocytes reside in the intima, they become intimal macrophages and internalize modified lipoproteins to be foam cells. Eventually, these macrophages congregate in a central core of atherosclerotic plaques (21).

Glucosamine is used to treat osteoarthritis (15), and it also exhibits anti-inflammatory actions. In brief, glucosamine suppresses neutrophil functions such as superoxide generation, granule enzyme release and chemotaxis (18). It also inhibits the aggregation of platelet (22). Glucosamine suppresses the cytokine-induced activation (such as nitric oxide, prostaglandin $\mathrm{E}_{2}$, IL-8 production) of synoviocytes (23). Furthermore, glucosamine inhibits ICAM-1 expression in human retinal pigment epithelial cells (19).

In this study, we investigated the effect of glucosamine on the activation of endothelial cells, and revealed that glucosamine but not $\mathrm{N}$-acetylglucosamine can inhibit the LL-37-induced expression of ICAM-1 and MCP-1 at both mRNA and protein levels (Figs. 1 and 2). In separate experiments, we stimulated endothelial cells with proinflammatory cytokines such as TNF- $\alpha$. We found that TNF- $\alpha$ induces the expression of MCP-1 and ICAM-1, and the expression was similarly suppressed by glucosamine as observed in the LL-37-induced expression of MCP-1 and ICAM-1 (data not shown).

Various cytoplasmic and nuclear proteins are modified at serine and/or threonine residues by $O$-linked-Nacetylglucosamine monosaccharides (24). Mammalian cells contain $O$-GlcNAc transferase (OGT), an O-GlcNAcmodification forming enzyme and $O-\mathrm{N}$-acetylglucosaminidase $(O$-GlcNAcase), an O-GlcNAc-modification degrading enzyme, and a gene disruption study shows that $O$-GlcNAc modification modulates cell functions (25). About one-quarter of identified $O$-GlcNAcylated proteins are involved in transcription or translation (20). Of note, it has been reported in the isolated heart that glucosamine increases cardiac $O$-GlcNAc levels and protects hearts from ischemia/ reperfusion-injury, and that alloxan, an OGT inhibitor blocks the protection (26). Furthermore, in isolated cardiomyocytes, both glucosamine and O-(2-acetamido-2-deoxy-Dglucopyranosylidene) amino-N-phenylcarbamate (PUGNAc), an O-GlcNAcase inhibitor, show protective effect against hypoxia and reoxygenation stress (27). In addition, glucosamine improves cardiac function in vivo in a rat trauma/ hemorrhage model, and this effect is associated with the increased cardiac $O$-GlcNAc levels (28). These observations suggest that glucosamine is likely to circumvent the excessive cell activation under various diseased conditions via $O$-GlcNAc modification. Thus, we focused on the $O$-GlcNAc modification to estimate the mechanism for the glucosamine-induced suppression of endothelial cell activation.

The data demonstrated that glucosamine can induce the $O$-GlcNAc modification in HUVEC, but $\mathrm{N}$-acetyl glucosamine can not (Fig. 3). Furthermore, alloxan, an OGT inhibiotor eliminated the inhibitory effect of glucosamine on ICAM-1 and MCP-1 expression (Fig. 4). Thus, because the effects of glucosamine, $\mathrm{N}$-acetylglucosamine and alloxan on $O$-GlcNAc modification levels are negatively parallel with those on the endothelial cell activation, we hypothesized that $O$-GlcNAc modification is one of the possible mechanism for the glucosamine-induced suppression of endothelial cell activation. In conclusion, glucosamine can inhibit LL-37-induced expression of ICAM- 1 and MCP-1, possibly via the $O$-GlcNAc modification. Usually, 1.5 or $3 \mathrm{~g}$ /day of glucosamine is administered to humans for treatment of osteoarthritis (18). We observed that serum glucosamine levels reached $>0.02 \mathrm{mM}$ after oral administration of $1.5 \mathrm{~g}$ glucosamine, as measured by a high performance liquid chromatography method using phenylisothiocyanate-derivatized glucosamine (29). Noticeably, in this study, glucosamine partially inhibited ICAM-1 and MCP-1 mRNA expression in vitro at concentrations of $>0.01 \mathrm{mM}$. Thus, it is tempting to speculate that glucosamine affects endothelial cell activation in vivo, thereby possibly exhibiting anti-inflammatory action on atherosclerosis. In this context, it is interesting to note that glucosamine administration significantly reduces the atherosclerotic lesion in aortic root of apoE-deficient mice (30). The in vivo effect of glucosamine on atherosclerotic disorders should be carefully evaluated in the future.

\section{Acknowledgements}

This study was supported in part by a grant from the Atopy (Allergy) Research Center, Juntendo University and a Grantsin-Aid for 21st Century COE Research from the Ministry of Education, Culture, Sports, Science and Technology, Japan.

\section{References}

1. Bailleul S, Couderc R, Rossignol C, Fermanian J, Boutouchent F, Farnier MA and Etienne J: Lipoprotein(a) in childhood: relation with other atherosclerosis risk factors and family history of atherosclerosis. Clin Chem 41: 241-245, 1995.

2. Hansson GK: Inflammation, atherosclerosis, and coronary artery disease. N Engl J Med 52: 1685-1695, 2005.

3. Bolick DT, Orr AW, Whetzel A, Srinivasan S, Hatley ME, Schwartz MA and Hedrick CC: 12/15-lipoxygenase regulates intercellular adhesion molecule-1 expression and monocyte adhesion to endothelium through activation of RhoA and NF-кB. Arterioscler Thromb Vasc Biol 25: 2301-2307, 2005.

4. Blanco-Colio LM, Munoz-García B, Martín-Ventura JL, Alvarez-Sala LA, Castilla M, Bustamante A, Lamuela-Raventós RM, Gómez-Gerique J, Fernández-Cruz A, Millán J and Egido J: Ethanol beverages containing polyphenols decrease nuclear factor kappa-B activation in mononuclear cells and circulating MCP-1 concentrations in healthy volunteers during a fatenriched diet. Atherosclerosis 192: 335-341, 2007.

5. Liu SX, Hou FF, Guo ZJ, Nagai R, Zhang WR, Liu ZQ, Zhou ZM, Zhou M, Xie D, Wang GB and Zhang X: Advanced oxidation protein products accelerate atherosclerosis through promoting oxidative stress and inflammation. Arterioscler Thromb Vasc Biol 26: 1156-1162, 2006. 
6. Braunersreuther V and Mach F: Leukocyte recruitment in atherosclerosis: potential targets for therapeutic approaches? Cell Mol Life Sci 63: 2079-2088, 2006.

7. Levy O: Antimicrobial proteins and peptides: anti-infective molecules of mammalian leukocytes. J Leukoc Biol 76: 909-925, 2004.

8. Gudmundsson GH, Agerberth B, Odeberg J, Bergman T, Olsson B and Salcedo R: The human gene FALL39 and processing of the cathelin precursor to the antibacterial peptide LL-37 in granulocytes. Eur J Biochem 238: 325-232, 1996.

9. Dürr UH, Sudheendra US and Ramamoorthy A: LL-37, the only human member of the cathelicidin family of antimicrobial peptides. Biochim Biophys Acta 1758: 1408-1425, 2006.

10. Nagaoka I, Hirota S, Niyonsaba F, Hirata M, Adachi Y, Tamura H and Heumann D: Cathelicidin family of antibacterial peptides CAP18 and CAP11 inhibit the expression of TNF- $\alpha$ by blocking the binding of LPS to CD14+ cells. J Immunol 167: 3329-3338, 2001.

11. De Yang, Chen Q, Schmidt AP, Anderson GM, Wang JM, Wooters J, Oppenheim JJ and Chertov O: LL-37, the neutrophil granule- and epithelial cell-derived cathelicidin, utilizes formyl peptide receptor-like 1 (FPRL1) as a receptor to chemoattract human peripheral blood neutrophils, monocytes, and T cells. J Exp Med 192: 1069-1074, 2000.

12. Nagaoka I, Tamura $\mathrm{H}$ and Hirata $\mathrm{M}$ : An antimicrobial cathelicidin peptide, human CAP18/LL-37, suppresses neutrophil apoptosis via the activation of formyl-peptide receptor-like 1 and P2X 7 . J Immunol 176: 3044-3052, 2006.

13. Edfeldt K, Agerberth B, Rottenberg ME, Gudmundsson GH, Wang XB, Mandal K, Xu Q and Yan ZQ: Involvement of the antimicrobial peptide LL-37 in human atherosclerosis. Arterioscler Thromb Vasc Biol 26: 1551-1557, 2006.

14. Ciornei CD, Tapper H, Bjartell A, Sternby NH and Bodelsson M: Human antimicrobial peptide LL-37 is present in atherosclerotic plaques and induces death of vascular smooth muscle cells: a laboratory study. BMC Cardiovasc Disord 6: 49, 2006.

15. Crolle G and D'Este E: Glucosamine sulphate for the management of arthrosis: a controlled clinical investigation. Curr Med Res Opin 7: 104-109, 1980.

16. Reginster JY, Deroisy R, Rovati LC, Lee RL, Lejeune E, Bruyere O, Giacovelli G, Henrotin Y, Dacre JE and Gossett C: Long-term effects of glucosamine sulphate on osteoarthritis progression: a randomised, placebo-controlled clinical trial. Lancet 357: 251-256, 2001.

17. Meininger CJ, Kelly KA, Li H, Haynes TE and Wu G: Glucosamine inhibits inducible nitric oxide synthesis. Biochem Biophys Res Commun 279: 234-239, 2000.

18. Hua J, Sakamoto K and Nagaoka I: Inhibitory actions of glucosamine, a therapeutic agent for osteoarthritis, on the functions of neutrophils. J Leukoc Biol 71: 632-640, 2002.
19. Chen JT, Liang JB, Chou CL, Chien MW, Shyu RC, Chou PI and Lu DW: Glucosamine sulfate inhibits TNF- $\alpha$ and IFN- $\gamma-$ induced production of ICAM-1 in human retinal pigment epithelial cells in vitro. Invest Ophthalmol Vis Sci 47: 664-672, 2006.

20. Wells L, Vosseller K and Hart GW: Glycosylation of nucleocytoplasmic proteins: signal transduction and O-GlcNAc. Science 291: 2376-2378, 2001

21. Galkina E and Ley K: Vascular Adhesion Molecules in therosclerosis. Arterioscler Thromb Vasc Biol 27: 2292-2301, 2007.

22. Hua J, Suguro S, Iwabuchi K, Tsutsumi-Ishii Y, Sakamoto K and Nagaoka I: Glucosamine, a naturally occurring amino monosaccharide, suppresses the ADP-mediated platelet activation in humans. Inflamm Res 53: 680-688, 2004.

23. Hua J, Sakamoto K, Kikukawa T, Abe C, Kurosawa H and Nagaoka I: Evaluation of the suppressive actions of glucosamine on the interleukin-1ß-mediated activation of synoviocytes. Inflamm Res 56: 432-438, 2007.

24. Schlummer S, Vetter R, Kuder N, Henkel A, Chen YX, Li YM, Kuhlmann J and Waldmann H: Influence of serine O-glycosylation or O-phosphorylation close to the vJun nuclear localisation sequence on nuclear import. Chembiochem 7: 88-97, 2006.

25. Shafi R, Iyer SP, Ellies LG, O'Donnell N, Marek KW, Chui D, Hart GW and Marth JD: The O-GlcNAc transferase gene resides on the $\mathrm{X}$ chromosome and is essential for embryonic stem cell viability and mouse ontogeny. Proc Natl Acad Sci USA 97: 5735-5739, 2000.

26. Liu J, Pang Y, Chang T, Bounelis P, Chatham JC and Marchase RB: Increased hexosamine biosynthesis and protein O-GlcNAc levels associated with myocardial protection against calcium paradox and ischemia. J Mol Cell Cardiol 40: 303-312, 2006.

27. Champattanachai V, Marchase RB and Chatham JC: Glucosamine protects neonatal cardiomyocytes from ischemiareperfusion injury via increased protein-associated O-GlcNAc. Am J Physiol Cell Physiol 292: C178-C187, 2007.

28. Yang S, Zou LY, Bounelis P, Chaudry I, Chatham JC and Marchase RB: Glucosamine administration during resuscitation improves organ function after trauma hemorrhage. Shock 25 : 600-607, 2006.

29. Liang Z, Leslie J, Adebowale A, Ashraf M and Eddington ND: Determination of the nutraceutical, glucosamine hydrochloride, in raw materials, dosage forms and plasma using pre-column derivatization with ultraviolet HPLC. J Pharm Biomed Anal 20: 807-814, 1999.

30. Duan W, Paka L and Pillarisetti S: Distinct effects of glucosamine on vascular endothelial and smooth muscle cells: evidence for a protective role for glucosamine in atherosclerosis. Cardiovasc Diabetol 4: 16, 2005. 